\title{
El Boletín de la Academia Mexicana de Cirugía
}

\author{
The Mexican Surgery Academy Bulletin
}

\author{
Ulises Rodríguez-Wong* \\ Academia Mexicana de Cirugía, Ciudad de México, México
}

La Academia Mexicana de Cirugía es una corporación científica dedicada a la investigación, el estudio, el fomento, el perfeccionamiento y el desarrollo educativo de las disciplinas médico-quirúrgicas. Así mismo, es Órgano Consultor del Gobierno Federal y de los Gobiernos Estatales, así como Vocal Titular del Consejo de Salubridad General.

Por otra parte, la Academia Mexicana de Cirugía forma parte del Cuerpo Consultivo de diferentes organismos gubernamentales y privados en las actividades que beneficien a la salud.

El Boletín de la Academia Mexicana de Cirugía se publicó por primera vez en febrero de 1997 (Fig. 1). La edición del Boletín es trimestral y en él se difunden las actividades internas que realizan los académicos a través de comisiones ${ }^{1}$, representaciones y otras actividades de carácter académico, social y cultural, así como las actividades que se desarrollan en colaboración con diferentes instituciones y asociaciones. También en el Boletín se difunden opiniones sobre los programas de salud del país y sobre otros asuntos médico-quirúrgicos de interés general.

Por ello, este medio informativo es sin duda un excelente canal de participación para todos los Señores Académicos, sobre sus actividades académicas y sociales tanto dentro de la propia Academia como en otras asociaciones nacionales o internacionales, cuando lleven la representación de esta organización.

Por otra parte, los aspectos históricos de la Academia, así como los de la Medicina y la Cirugía en nuestro país, son también temas que es necesario rescatar y mantener en la memoria, honrando de esta manera el trabajo de los médicos que han sentado las bases de estas disciplinas en nuestro país.

También tienen cabida en el Boletín temas de difusión científica de interés general que permitan informar, de manera concisa, sobre avances médicos y quirúrgicos, prevención y detección oportuna de algunos padecimientos, seguridad del paciente quirúrgico, bioética, calidad y calidez de la atención médica, entre otros tópicos de interés.

El Boletín también cumple con la misión de informar sobre las distinciones académicas y los reconocimientos que reciban los Señores Académicos, tanto en nuestro país como en el extranjero.

Los Capítulos en la provincia de la Academia Mexicana de Cirugía tienen una participación activa dentro del Boletín, difundiendo las actividades de los Académicos en las diversas entidades federativas.

No cabe duda de que difundir el quehacer de las actividades del ser humano ha sido una necesidad desde tiempos ancestrales; ya las pinturas rupestres plasmaban a los hombres primitivos cazando o luchando por su supervivencia. Poco a poco se desarrollaron algunas formas de transmisión escrita del conocimiento, y algunas de ellas han perdurado, en tanto que otras no; sin embargo, de esta manera ha quedado evidencia de la actividad del hombre en las diferentes etapas de la historia, dejando además huella de sus conocimientos, mismos que han permitido al hombre continuar en la senda del desarrollo de la civilización².

\author{
Correspondencia: \\ *Ulises Rodríguez-Wong \\ Tepic, 113, interior 611 \\ Col. Roma Sur \\ C.P. 06760 , Ciudad de México, México \\ E-mail: ulisesromed@ prodigy.net.mx
}

Fecha de recepción: 20-10-2018

Fecha de aceptación: 15-12-2018

DOI: $10.24875 / C I R U .18000818$
Cir Cir. 2019;87:253-254

Contents available at PubMed www.cirugiaycirujanos.com 


\section{BOLETÍN}

ACADEMIA MEXICANA DE CIRUGÍA No. 1 HEBRIRO DE 1997

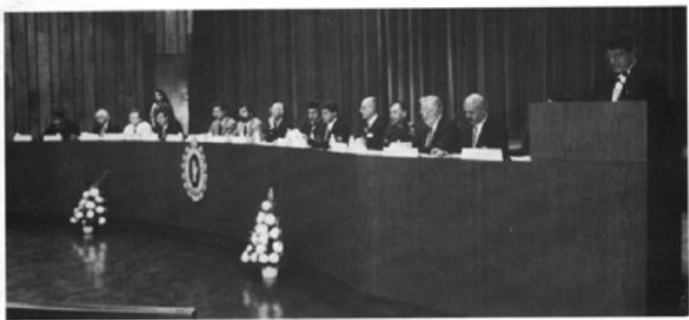

Sesión solemne de iniciación de labores del LXIV año

CONTENIDO

Figura 1. Portada del primer número del Boletín de la Academia Mexicana de Cirugía en 1997.

Desde el punto de vista de la historicidad, toda la actividad del ser humano forma parte de la historia. De acuerdo con Heidegger, la historia es un

acontecer que ocurre con el pasar del tiempo, y lo que ha sido es un pasado que no deja de ser $^{3}$.

Después de un breve tiempo de haberse interrumpido la publicación del Boletín de la Academia Mexicana de Cirugía, nuevamente se publicó a partir del tercer trimestre del año 2017, reanudando sus actividades de difusión cultural y científica en beneficio de la comunidad médica.

\section{Conflicto de intereses}

El autor declara no tener ningún conflicto de intereses.

\section{Bibliografía}

1. De la Torre-Bravo A. 20 años del Boletín. Bol Acad Mex Cir. 2017;20:5-6.

2. Rodríguez-Wong U. Nueva época del Boletín de la Academia Mexicana de Cirugía. Bol Acad Mex Cir. 2017;20:3-4.

3. Heidegger M. El ser y el tiempo. Traducción de José Gaos. México: Fondo de Cultura Económica; 1993. p. 30. 